\title{
Respondendo questões intrigantes e complexas a pessoas curiosas e interessadas em aprender Física: o sítio "Pergunte ao CREF"
}

Answering intriguing and complex questions to people curious and interested in learning physics: the site "Ask CREF"

\author{
Fernando Lang da Silveira*10 \\ ${ }^{1}$ Universidade Federal do Rio Grande do Sul, Instituto de Física, Porto Alegre, RS, Brasil.
}

Recebido em 22 de outubro de 2020. Aceito em 23 de outubro de 2020.

\begin{abstract}
O artigo comemora os dez anos do sítio de perguntas e respostas desenvolvido junto ao Centro de Referência para o Ensino da Física (CREF) do IF-UFRGS. São questões e dúvidas, a maioria intrigante e algumas de natureza complexa, cujas respostas dificilmente são encontradas na literatura de física. A descrição, evolução, abrangência e impacto do sítio junto à comunidade lusófona de professores e alunos são abordadas. Apresentam-se também as dez questões mais acessadas do sítio e, como exemplos, seis postagens completas.
\end{abstract}

Palavras-chave: Perguntas sobre Física, Dúvidas de Física, Divulgação científica.

The article celebrates the ten years of the question-and-answer website developed at the Reference Center for Teaching Physics (CREF) of the Federal University of Rio Grande do Sul. These are questions and doubts, most intriguing and some of a complex nature, whose answers are hardly found in the physics literature. The description, evolution, scope and impact of the site with the Portuguese-speaking community of teachers and students are discussed. Also presented are the ten most accessed questions on the site and, as examples, six complete posts.

Keywords: Questions about Physics, Doubts about Physics, Scientific Dissemination.

\section{Introdução}

Há vários sítios e blogs que se destinam a responder questões de alunos. Muitos deles focam em respostas a questões pontuais sobre problemas que o aluno se defronta na elaboração de suas tarefas escolares. Muitos poucos estão interessados em responder questões intrigantes, saciando a curiosidade de pessoas interessadas em aprender Física e penetrar nos seus mistérios e sutilezas. Exemplos de perguntas e dúvidas:

- É diferente a pressão em um botijão de GLP de $13 \mathrm{~kg}$ e $45 \mathrm{~kg}$ ?

- No fio neutro de nossa casa passa corrente elétrica?

- Qual é a força de impacto da laranja que atingiu o para-brisas do automóvel?

- Por que lentes de óculos fazem sombras?

- É possível determinar a pressão na cabine de um avião 5 dias depois de ter ocorrido o voo?

- Água aquecida no forno de micro-ondas pode explodir?

- Qual é razão para o chiado na chaleira antes de a água ferver?

\footnotetext{
*Endereço de correspondência: lang@if.ufrgs.br.
}

Tais dúvidas, que intrigam algumas pessoas, raramente seriam dirimidas buscando as referências bibliográficas de Física de ensino médio ou superior. Uma alternativa é recorrer ao sítio Pergunte ao $C R E F$, sobre o qual versa este trabalho 1 .

O sítio Pergunte ao CREF [2] existe desde maio de 2010, junto ao Centro de Referência para o Ensino da Física (CREF), tendo iniciado com a transposição de perguntas respondidas pelo autor deste trabalho no Yahoo Respostas [3]. O sítio, exclusivamente em português, em junho de 2013 passou a ser monitorado pelo Google Analytics. Possui atualmente 1418 questões respondidas por professores do IF-UFRGS ou convidados.

Este trabalho apresenta uma descrição de cerca de 8,3 milhões de visualizações de página em sete anos e quatro meses de monitoramento. Neste período de tempo observa-se um crescimento no número de visualizações de página por mês de cerca de 15 mil para 200 mil, distribuídos em sua maior parte no Brasil (93,7\%), entretanto, atingindo mais de uma centena de países. Entre os países destacam-se por ordem de visualizações Portugal, Estados Unidos, Moçambique, Angola, Índia, França, Alemanha, Reino Unido, Espanha e Japão. No Brasil os acessos estão distribuídos por 1539 cidades de todos os 
estados, com prevalência de São Paulo, seguido de Minas Gerais, Rio Grande do Sul, Rio de Janeiro, Paraná, Santa Catarina, Bahia e todas as demais unidades da federação.

\section{Um Sítio com Perguntas \& Respostas sobre Física}

No Pergunte ao CREF são respondidas perguntas e dúvidas conceituais sobre variados assuntos de Física, Matemática, História e Filosofia da Ciência, produzidas por qualquer pessoa que preencha o formulário disponível para tal fim.

Atualmente (30/09/2020) há 1418 postagens, distribuídas em 48 categorias, respondendo dúvidas específicas nos diversos assuntos relacionados no parágrafo anterior. São encontrados também 2983 comentários de usuários distribuídos pelas postagens.

As respostas foram produzidas por 42 professores do IF-UFRGS e por 17 convidados externos. A apresentação das questões no Índice Geral [4] segue o ordenamento temporal da postagem de suas respostas, havendo a possibilidade de localizar perguntas específicas por um sistema de busca por palavras-chave ou pela escolha de alguma das 48 categorias de assuntos.

Nas próximas seções são apresentadas algumas estatísticas relativas às visualizações das postagens.

\section{As Visualizações das Postagens do CREF}

O gráfico da Figura 1 apresenta a frequência de visualizações de páginas mensais no sítio desde primeiro de junho de 2013 até 30 de setembro de 2020.

Conforme evidencia o gráfico da Figura 1 houve um crescimento nas visualizações mensais por um fator de aproximadamente treze neste intervalo de oitenta e sete meses. No início (junho de 2013) havia cerca de 15 mil visualização por mês e no final há aproximadamente 200 mil visualizações mensais.

Atualmente ocorrem entre cinco e dez mil visualizações diárias no sítio, perfazendo o total de 8,3 milhões de visualizações de páginas no período oitenta e sete meses conforme o Google Analytics. Os contadores do próprio CREF registam quase 10,9 milhões de visualizações no mesmo período.

\section{Distribuição Geográfica das Sessões no CREF}

No intervalo de tempo de oitenta e sete meses o total de 8,3 milhões de visualizações de páginas teve um tempo médio de $3 \min 40$ s por visualização.

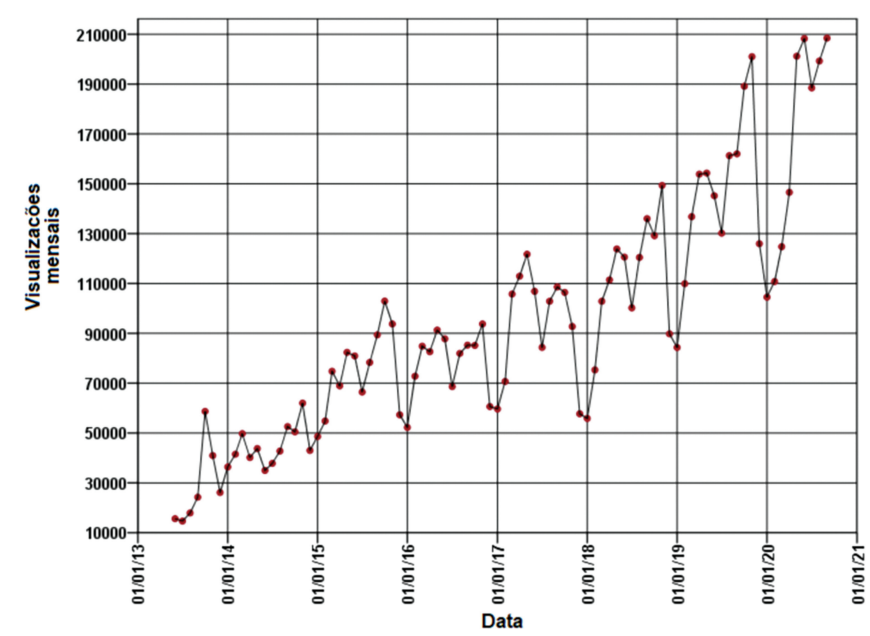

Figura 1: Frequência de acessos mensais ao longo de oitenta sete meses.

O mesmo usuário pode acessar em cada sessão mais de uma página ou questão respondida. Houve um total 6,5 milhões sessões registradas; deste total, 93,7\% aconteceu no Brasil e o restante $6,3 \%$ em duas centenas de diferentes países. A Figura 2 é uma representação espacial da distribuição das sessões por todo o mundo produzida pelo Google Analytics.

Conforme se observa na Figura $3,55 \%$ das sessões fora do Brasil aconteceram em Portugal, ocorrendo também em outros países de língua portuguesa e em nações onde o idioma oficial não é o português, como por exemplo EUA, França, Alemanha. Por outro lado, há poucas sessões originadas na América do Sul, exceto o Brasil.

A Figura 4 é uma representação da distribuição de sessões no Brasil, indicando que todo o território nacional está representado.

A Figura 5 apresenta em um gráfico de barras a distribuição das sessões pelas diversas unidades da federação. O estado de São Paulo (27\%), seguido do Minas Gerais (11\%) lideram a distribuição de sessões. Entretanto o sítio tem sido frequentado por todas as unidades federativas, através de 1539 cidades, sendo que da capital São Paulo se originam 12,5\% das sessões, seguida do Rio de Janeiro com 7,6\% e de Porto Alegre com $5,1 \%$.

\section{As Postagens com Maior Número de Visualizações}

Para se ter uma ideia sobre os temas preferidos pelos usuários do Pergunte ao CREF apresenta-se no Quadro 1 as dez postagens com maior número de visualizações e em seguida alguns comentários.

Seguem comentários sobre algumas das postagens relacionadas no Quadro 1 


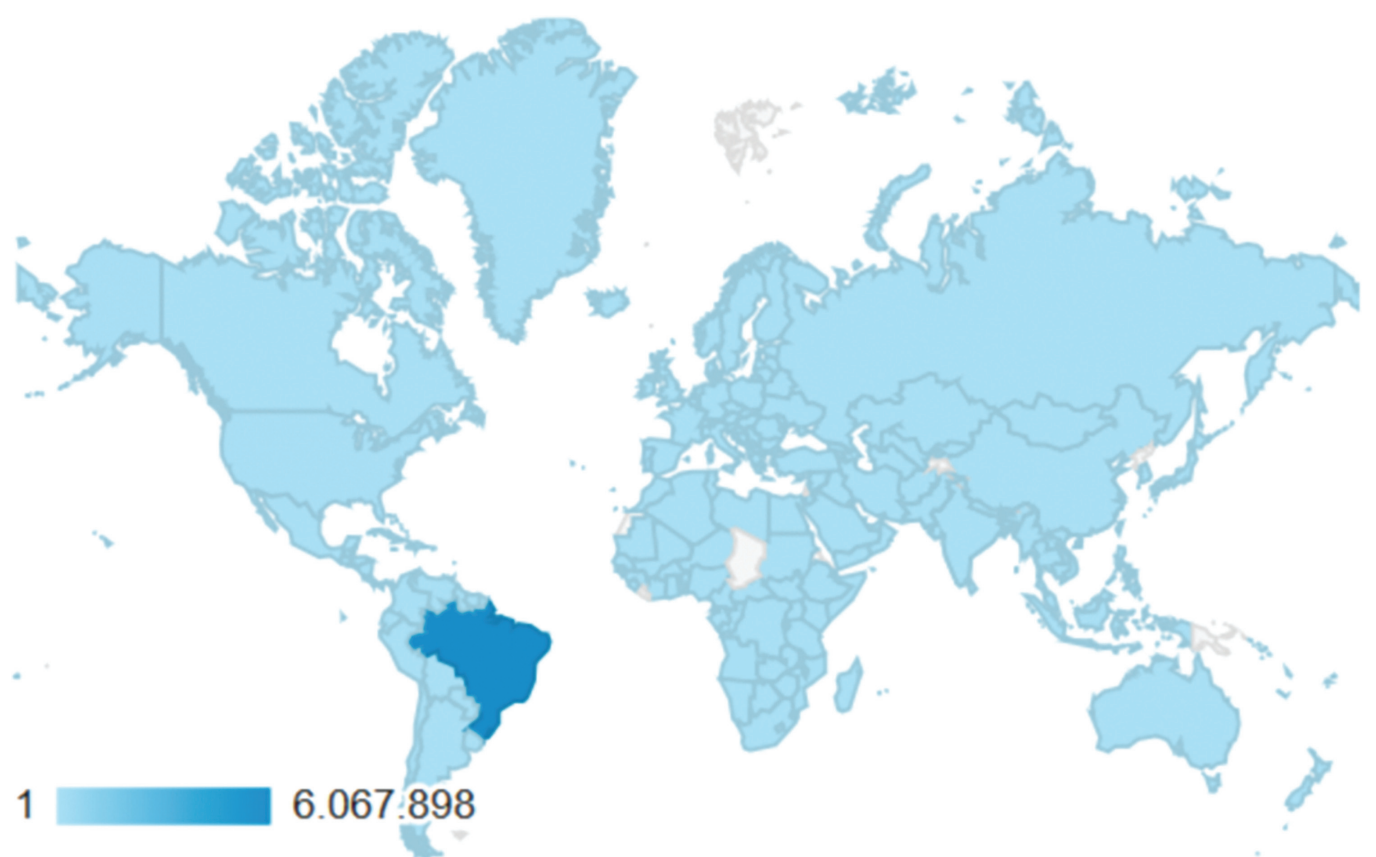

Figura 2: Distribuição global das sessões em 201 países.

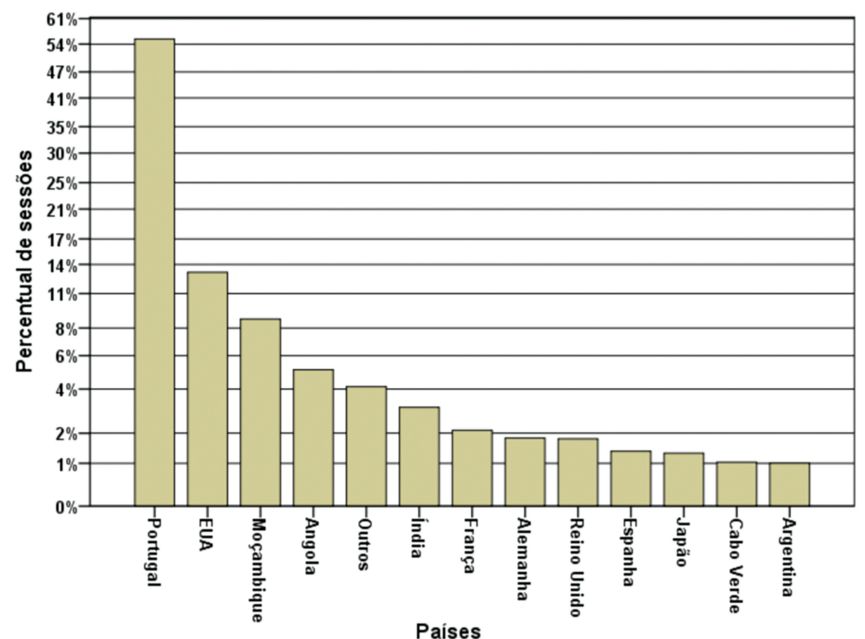

Figura 3: Distribuição das sessões por países fora do Brasil.

Força de impacto - Por ser o tema mais recorrente no CREF, originou uma categoria especial que abrange 34 postagens, duas delas com mais de 100 mil visualizações.

O questionamento recorrente diz respeito ao cálculo do valor da força de impacto em variadas situações: do corpo em queda que colide com o solo ou com a água, do automóvel que colide com outro ou com um obstáculo, do projétil de arma de fogo que atinge o alvo,....

Um número grande de questionamentos sobre este tema tem sido respondido diretamente aos perguntantes, indicando as postagens que os elucida.

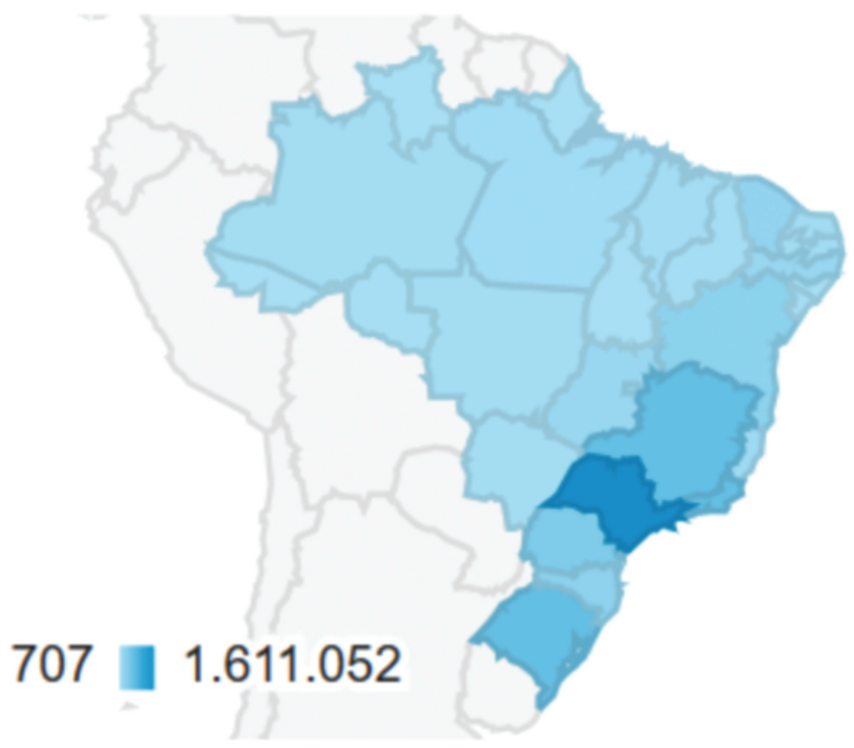

Figura 4: Distribuição das sessões no Brasil.

No fio neutro da nossa casa passa corrente? - Tratase de um tema que também está presente em algumas outras, explicitando a dificuldade que os perguntantes tem em compreender que no condutor denominado de neutro em uma instalação elétrica possa existir uma corrente elétrica.

A pressão é diferente em um botijão de gás de 13 $\mathrm{kg}$ e $45 \mathrm{~kg}$ ? - A resposta discute o comportamento contra intuitivo de que a pressão nos botijões é a pressão 


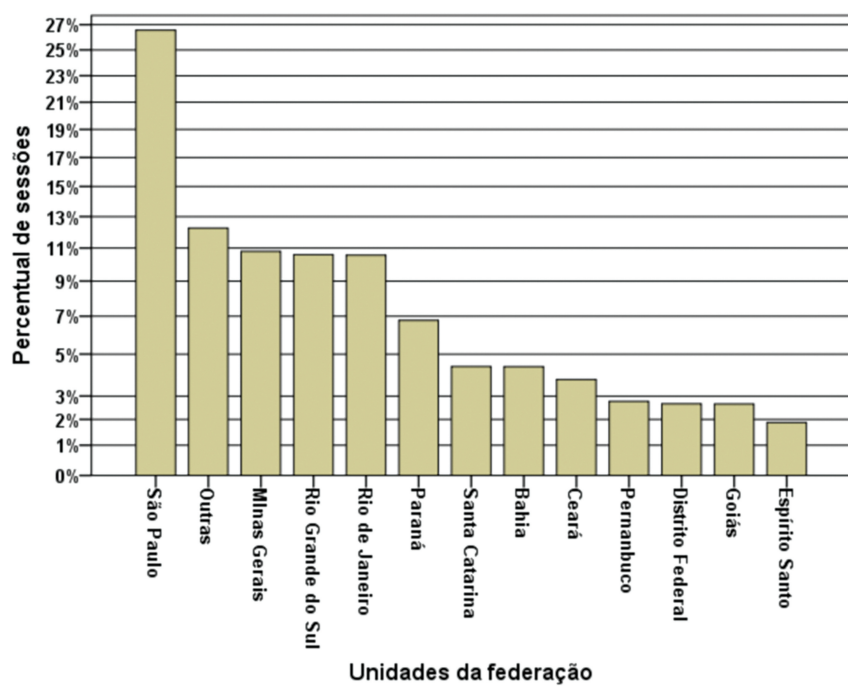

Figura 5: Distribuição das sessões por todas as unidades federativas do Brasil.

do vapor em equilíbrio com a sua fase líquida e que, portanto, independe da capacidade e da quantidade de fluido no botijão.

O formato da Terra - Esta postagem, juntamente como muitas outras, trata do tema da Figura de nosso planeta em contraste com a concepção de Terra Plana tão em voga nas redes sociais.

Por que o efervescente primeiro desce na água e depois de alguns segundos sobe? - É surpreendente a procura por resposta para este efeito. Na postagem é referido um simples e intrigante experimento com bolinhas de naftalina que circulam em água carbonatada muito tempo.

Propulsão de foguetes no espaço: como é possível o empuxo se não existe atmosfera? - O negacionismo sobre a possibilidade de viagens espaciais fica evidente em mais de uma centena de comentários visíveis na postagem. Como os comentários do Pergunte ao CREF passam por moderação, algumas dezenas deles, por serem agressivos e chulos, foram suprimidos.

Os títulos das dez postagens mais visualizadas evidenciam uma heterogeneidade de temas e assuntos de Física. Grande parte dos questionamentos do CREF diz respeito a problemas enfrentados no dia a dia, cujas respostas não são facilmente encontradas na literatura de sala de aula. Há também muitas dúvidas suscitadas por problemas tipicamente acadêmicos, mas pelas regras do sítio só são respondidas questões conceituais, de modo que exercícios usualmente propostos como tarefas aos alunos, se postados no sítio, não são respondidos.

\section{Exemplos de Postagens no Pergunte ao CREF}

No Apêndice alguns exemplos de postagens do Pergunte ao CREF são encontrados.

Como foi notado na seção anterior o tema do valor da força de impacto aparece em dezenas de perguntas, em variadas circunstâncias que vão desde o impacto de projéteis de arma de fogo até o de queda de corpos atingindo o solo ou a água. No Apêndice a postagem A1 diz respeito a uma laranja que se espatifa no para-brisas

Quadro 1: As dez postagens mais acessadas no sítio Pergunte ao CREF: endereço da postagem, total de visualizações e título. Visualizações de 30 set. 2020.

\begin{tabular}{|c|c|c|}
\hline Endereço & Total de visualizações & Título \\
\hline https://bit.ly/3lbf3F5 & $722 \mathrm{mil}$ & Força de impacto \\
\hline https://bit.ly/2SriR8S & 116 mil & No fio neutro da nossa casa passa corrente? \\
\hline https://bit.ly/2Sn6Dy9 & 112 mil & $\begin{array}{l}\text { A pressão é diferente em um botijão de gás de } 13 \mathrm{~kg} \text { e } 45 \\
\mathrm{~kg} \text { ? }\end{array}$ \\
\hline https://bit.ly/3le5EfS & $100 \mathrm{mil}$ & Como o Sol é uma bola de fogo se lá não existe oxigênio? \\
\hline https://bit.ly/33sgVmW & $100 \mathrm{mil}$ & $\begin{array}{l}\text { Chuveiro elétrico: por que não levamos choque se água está } \\
\text { em contato com a parte eletrificada do resistor de } \\
\text { aquecimento? }\end{array}$ \\
\hline https://bit.ly/3lcuAo3 & 76 mil & Estrelas piscam com cores diversas: qual é a razão? \\
\hline https://bit.ly/30vPg2k & 76 mil & O formato da Terra \\
\hline https://bit.ly/3lbgrrh & $72 \mathrm{mil}$ & Intensidade da corrente elétrica perigosa para humanos \\
\hline https://bit.ly/2HXRBgf & $68 \mathrm{mil}$ & $\begin{array}{l}\text { Por que o efervescente primeiro desce na água e depois de } \\
\text { alguns segundos sobe? }\end{array}$ \\
\hline https://bit.ly/3iuPNYA & $58 \mathrm{mil}$ & $\begin{array}{l}\text { Propulsão de foguetes no espaço: como é possível o empuxo } \\
\text { se não existe atmosfera? }\end{array}$ \\
\hline
\end{tabular}


de um automóvel, motivando posteriormente um instrutor de motoristas, que se diz incapaz de acompanhar o raciocínio, os termos usados na matemática aplicada, a buscar uma resposta qualitativa para explicar de forma simples as forças envolvidas em um impacto/colisão com outros veículos, já que instrui pessoas para a direção defensiva. A resposta lhe foi dada na postagem A2.

A postagem A3 responde a um produtor de biogás sobre a possibilidade por ele aventada de armazenar o excedente de metano gerado em botijões de GLP. O seu intuito era estocar massas de biogás comparáveis àquelas encontradas no botijão abastecido com GLP. A razão para que sua expectativa não seja realizável é apresentada e ele, ao final, agradece as informações recebidas.

A consulta de um aluno de artes da Universidade do Porto na postagem A4, interessado em entender um detalhe intrigante na célebre pintura de Narciso por Caravaggio, ensejou uma discussão sobre imagens em espelhos planos, revelando que o pintor compreendia muito bem sobre a percepção da imagem de Narciso no espelho de água.

Dúvidas motivadas por conteúdos comuns em disciplinas de Física do ensino médio e superior são encontradas no Pergunte ao CREF a exemplo da postagem A5 que trata da interpretação de tempos negativos em soluções de problemas de Cinemática.

A postagem A5 aborda um tema polêmico sobre a possibilidade de um barco a vela se mover quando um ventilador solidário ao barco sopra sobre sua vela. A afirmação incondicional negando a possibilidade do barco se mover é encontrada em livros texto de Física e em questões de vestibular. Entretanto, conforme se discute na postagem, é possível teoricamente que um barco em tal circunstância seja movido e a concretização dessa possibilidade está demonstrada em um vídeo.

\section{Comentários Finais}

O gradual ganho de visibilidade do Pergunte ao CREF ocorreu graças às postagens das questões (mas não de suas respostas, pois estas somente estavam acessíveis no sítio) em dezenas de comunidades de Física do Facebook. Em mais de 30 comunidades no FB as postagens do CREF têm sido sistematicamente divulgadas.

Entretanto, atualmente a expansão do número de visualizações decorre de que muitas pesquisas com o Google colocam no topo dos resultados da busca nosso sítio.

O Pergunte ao CREF se tornou uma referência para muitos professores, estudantes e interessados em Física, ultrapassando as expectativas que motivaram sua criação. Com frequência as perguntas são formuladas por professores, que não souberam respondê-las, quando questionados por seus alunos; outras vezes por leigos, preocupados com questões do dia a dia. Por vezes, os professores tomam conhecimento do sítio, via seus alunos, participantes das redes sociais. Registre-se que as redes sociais são excelentes meios de divulgação, porém o material nelas postado é efêmero. Manter a coletânea de perguntas \& respostas no servidor da Universidade Federal do Rio Grande do Sul (UFRGS), além de conferir um selo de qualidade, garante a preservação do material.

Em síntese, o Pergunte ao $C R E F$, tornou-se não apenas uma forma de divulgação científica que atende uma ampla comunidade, mas também um recurso didático precioso para professores que queiram inovar os conteúdos abordados em sala de aula.

No momento em que se encerrava este relato foi inaugurada uma nova secção no Pergunte ao CREF, contendo vídeos no Youtube, sobre os temas desenvolvidos no sítio [5].

Terminamos com uma citação literal de um professor de ensino médio:

O Pergunte ao CREF é um canal de comunicação que tem levado ao Facebook e às nossas aulas ciência de verdade e, principalmente, Física correta!

\section{Apêndice}

A.1 - Força de impacto de uma laranja em
\begin{tabular}{|l} 
um para-brisas de um veículo em movimento - \\
https://urless.in/6BFKG
\end{tabular}

Olá. já estou há horas fazendo um cálculo mas não estou conseguindo ter o resultado. É o seguinte, uma vez, meu amigo e eu estávamos em um ônibus, na rodovia voltando para nossa cidade. quando um teste que estávamos fazendo deu errado e quase causou um acidente. Como não vi o que aconteceu depois, fiquei curioso para saber o que poderia ter acontecido. Uma laranja de aproximadamente 200 gramas, foi lançada da janela do ônibus, e sem querer, por falta de atenção nossa, atingiu o para brisas de um carro que estava vindo na outra mão, e espatifou no ar. O ônibus estava a uma velocidade de $90 \mathrm{~km}$ por horas, estava descendo. Já o carro estava vindo a uns 100 a $110 \mathrm{~km}$ por hora. Qual a força de impacto da laranja no para brisas do veículo?

\section{RESPOSTA:}

Vocês cometeram uma infração pois não se arremessa pela janela de veículos qualquer tipo de objeto não importando que a intenção seja "nobre" como a de realizar um teste.

O módulo da velocidade $(V)$ da laranja em relação ao para-brisa no momento da colisão pode ser avaliada em cerca de $200 \mathrm{~km} / \mathrm{h}$ ou $56 \mathrm{~m} / \mathrm{s}$. Ao colidir com o parabrisa sem o penetrar, a velocidade do centro de massa da laranja em relação ao para-brisa é nula em algum momento. Desta forma, usando-se a conhecida Equação de Torricelli, pode-se estimar a aceleração média sofrida pela laranja desde o momento que se inicia o impacto 
até o momento em que a velocidade é nula como

$$
A \approx \frac{V^{2}}{2 X}
$$

onde $X$ é o valor do deslocamento do centro de massa da laranja neste processo de frenagem. A força média $(F)$ de impacto é estimada como o produto da massa $M$ da laranja pela aceleração média, chegando-se assim a

$$
F \approx M \frac{V^{2}}{2 X}
$$

No caso da laranja, que por ser facilmente deformável se esborracha contra o para-brisa, o deslocamento $X$ é o máximo possível e igual a metade do diâmetro $D$ da laranja. Então $X=D / 2$, que substituído na equação 1 leva a uma força média dada por

$$
F \approx \frac{M V^{2}}{D}
$$

O diâmetro de uma laranja é aproximadamente $10 \mathrm{~cm}$ ou $0,1 \mathrm{~m}$ e dado que a massa da laranja é $0,2 \mathrm{~kg}$ e a velocidade tem o valor de $56 \mathrm{~m} / \mathrm{s}$, a força média resulta em

$$
F \approx \frac{0,2.56^{2}}{0,1} \cong 6300 N \cong 640 \mathrm{kgf}
$$

O para-brisa é capaz de resistir a este impacto de curtíssima duração porque a força está distribuída sobre uma área grande já que a laranja se espatifa, sendo a energia cinética parcial ou totalmente dissipada dentro da laranja ao invés de ser absorvida no para-brisa.

Importante notar também que, de acordo com a equação (2), quanto menor é $X$ (o que significa que o corpo que atinge o para-brisa é menos deformável), maior será a força média de impacto. Portanto, um corpo resistente como uma pedra terá um efeito catastrófico sobre o para-brisa pois além da rigidez da pedra, a força de impacto estará concentrada sobre uma pequena região, gerando enorme pressão.

A.2 - Uma explicação qualitativa para a intensidade da força de impacto - https://urless.in/2VSoO

Bom dia. Recentemente ví um artigo que é de meu interesse: Força de impacto de uma laranja em um para-brisas de um veículo em movimento https://urless.in/6BFKG). Porém, apesar de bem explicado, não consegui acompanhar o raciocínio. Os termos usados na matemática aplicada não são de meu conhecimento. Poderia me ajudar explicando de modo mais simples?

Necessário se faz de minha parte explicar melhor o motivo de meu pedido. Sou instrutor de motoristas de caminhão e ônibus, para os quais aplico entre outras matérias DIREÇÃO DEFENSIVA.

Minha intenção é explicar de forma simples as forças envolvidas em um impacto/colisão com outros veículos no sentido contrário, para conscientizá-los de suas responsabilidades quando nos volantes de um auto.

Não tenho estudo e não sou capaz de desenvolver o raciocínio necessário para acompanhar a postagem.

Parabenizo-o pela capacidade de compreender os mistérios das ciências e desejo-lhe vida longa e próspera.

\section{RESPOSTA:}

Para conseguir fazer estimativas dos valores das forças exercidas em colisões, é preciso argumentar com base em equações da dinâmica, como o Prof. Lang fez para calcular a força da laranja sobre o vidro em Força de impacto de uma laranja em um para-brisas de um veículo em movimento (https://urless.in/6BFKG). Porém, caso se queira ter uma ideia geral sobre os principais fatores envolvidos em problemas de colisão frontal, pode-se dizer que:

- a intensidade da força de impacto depende de quão deformável são os dois objetos que se chocam. Suponha dois objetos esféricos do mesmo tamanho e mesma massa, que se chocam com uma parede de aço. Quanto mais rígido for o objeto, mais rapidamente sua velocidade diminui durante o choque. No caso de um objeto flexível, como uma laranja, o objeto vai se deformando enquanto vai diminuindo a velocidade, e isso faz com que o tempo para parar seja maior do que para um objeto duro, como uma pedra. Assim, as forças envolvidas no choque de objetos flexíveis são menores, comparadas às envolvidas no choque de objetos duros. Se em vez de uma laranja fosse uma pedra, que não se deforma, teria que parar quase que instantaneamente, o que envolveria forças maiores no choque do que no caso da laranja (supondo que pedra e laranja tenham a mesma massa). É por isso que os para-choques de automóveis, feitos antigamente de materiais rígidos, passaram a ser construídos com materiais deformáveis (plásticos); para que parte da energia do impacto seja empregada na deformação do para-choques, também diminuindo a rapidez com a qual a velocidade dos veículos em colisão variam;

- a intensidade da força de impacto depende da massa dos corpos. Suponha dois corpos esféricos de mesmo tamanho e mesma flexibilidade que se chocam com uma parede de aço. Quanto maior a massa do corpo, maior será a força necessária para pará-lo;

- a intensidade da força de impacto depende, ainda, como as forças se distribuem nos corpos no instante do choque. Imagine dois dados idênticos que se chocam contra uma parede. Se um deles se chocar de quina e o outro se chocar com uma das faces na parede, o efeito será diferente;

- quanto maior a velocidade de aproximação entre os dois corpos deformáveis que se chocam, maiores 
serão os danos causados. Note que se um corpo está parado em relação à estrada e o outro está se movendo, a $60 \mathrm{~km} / \mathrm{h}$, no sentido do que está parado, a velocidade de aproximação deles é de $60 \mathrm{~km} / \mathrm{h}$. Porém, se cada um deles se move a $60 \mathrm{~km} / \mathrm{h}$, um de encontro ao outro, a velocidade de aproximação é de $120 \mathrm{~km} / \mathrm{h}$ ! Esse é um dos grandes problemas de choques frontais: o que importa é a soma dos valores registrado nos velocímetros dos dois carros.

A.3 - Armazenando metano em botijões de gás de cozinha - https://urless.in/X0ALW

Caro professor Fernando

Encontrei seu endereço na internet e entro em contato pois tenho uma dificuldade e gostaria que vc me ajudasse. Eu tenho um biodigestor para produzir metano. Eu quero armazenar metano e pensei em usar botijões de gás de cozinha. Quando comprimo o metano no botijão até uma pressão permitida para tais recipientes, observo ao pesar o botijão que tem pouco peso de gás dentro dele. Não consigo liquefazer o metano e gostaria de saber como resolver isso. Espero não incomodar vc e agradeço antecipadamente. Genivaldo.

\section{RESPOSTA:}

Caro Genivaldo,

Para liquefazer uma amostra gasosa (na verdade somente vapor pode ser liquefeito), a temperatura da amostra deve ser inferior à temperatura crítica da substância. Somente abaixo da temperatura crítica a substância pode se apresentar no estado líquido, devendo também a pressão ser igual ou superior à pressão de vapor saturado da substância.

Ou seja, se uma amostra gasosa estiver acima da temperatura crítica, não é possível por simples aumento de pressão fazê-la passar para o estado líquido. A temperatura crítica do metano é cerca de $-83^{\circ} \mathrm{C}$ (nesta temperatura a pressão para liquefazer pressão crítica - é cerca de 46atm). Desta forma, na temperatura ambiente o metano é gás e não pode ser liquefeito por mais que se aumente a pressão.

O "gás de cozinha" - GLP - na temperatura ambiente pode ser liquefeito pois sua temperatura crítica é superior à temperatura ambiente; na verdade a fase gasosa do "gás de cozinha" em um botijão é vapor. Designa-se como vapor a fase gasosa de uma substância abaixo da sua temperatura crítica.

A única forma de armazenar metano à temperatura ambiente é de fato como gás comprimido e, portanto, para armazenar massas comparáveis à massa de "gás de cozinha" em um botijão, somente é possível a altas pressões (e ainda assim não estará liquido), tornandose inviável pois o botijão explodiria muito antes disso. O GNV é basicamente metano e nos reservatórios dos automóveis, com volume da ordem de 100 litros, somente torna-se possível armazenar uma quantidade razoável de metano porque o reservatório é suficientemente resistente para suportar a pressão de armazenamento que é cerca $220 \mathrm{~atm}$.

Então, sob a pressão de 220 atm ou 3200 psi, se armazena no tanque de 100 litros uma massa de metano (ou melhor, de GNV) de cerca de $15 \mathrm{~kg}$.

Se tentares armazenar metano em um botijão de gás de cozinha, onde a pressão máxima possível não excede 15 atm, terás cerca de $1 \mathrm{~kg}$ apenas!

É possível armazenar metano líquido na pressão de 1 atm se a temperatura for cerca de $-160^{\circ} \mathrm{C}$. O armazenamento e transporte de grandes quantidades de GNV pode ser feito em tanques especiais, em baixa pressão (1 atm) e baixa temperatura $\left(-160^{\circ} \mathrm{C}\right)$.

Comentário do perguntante: Agora eu entendi professor. Vejo então que só posso armazenar pouco gás em um botijão e não tem como fazer diferente. A sua resposta foi muito boa. Obrigado!

A.4 - Pintura de Narciso por Caravaggio
https://urless.in/B1rma

Caro Professor Fernando Lang Silveira, boa tarde.

Meu nome é Ricardo Barbosa, estou a frequentar o $1^{\circ}$ ano do curso de História da Arte na Faculdade de Letras da Universidade do Porto, Portugal e estou a fazer um trabalho sobre o quadro Narciso de Caravaggio. Estava a fazer uma pesquisa sobre um pormenor que me parece ser relevante para o trabalho e li um pequeno texto do Professor (Por que ocorre reflexo da paisagem na superfície da água? - https://urless.in/XfzEV).

Não sou entendido em física, mas gostaria de colocar a seguinte questão: O reflexo na água de Narciso não tem o mesmo tamanho que o original, ou seja, o reflexo é sempre um pouco mais pequeno e afastado do original, certo? Isto acontece por causa da luz? Não acontece como num espelho em que a imagem e o original são simétricos, certo?

Pergunto isto, porque ao fazer a análise iconográfica para tentar perceber se Caravaggio usou algum critério geométrico na pintura, a imagem parece estar um pouco deslocada do original, por isso é que lembrei-me de fazer uma pesquisa nesse sentido para garantir que faz sentido referir no trabalho?

O Professor pode, por favor, ajudar-me a esclarecer esta dúvida? Muito obrigado. Cumprimentos.

\section{RESPOSTA:}

A superfície da água na qual Narciso se olha é um espelho plano, embora não seja metálico como são aqueles do nosso cotidiano.

A imagem conjugada por um espelho tem exatamente as mesmas dimensões do objeto, que neste caso é Narciso.

Entretanto esta pintura retrata Narciso de um ponto em relação ao qual o rosto de Narciso está mais próximo de Caravaggio do que a imagem do rosto de Narciso está do pintor. De fato na pintura o tamanho do rosto do 


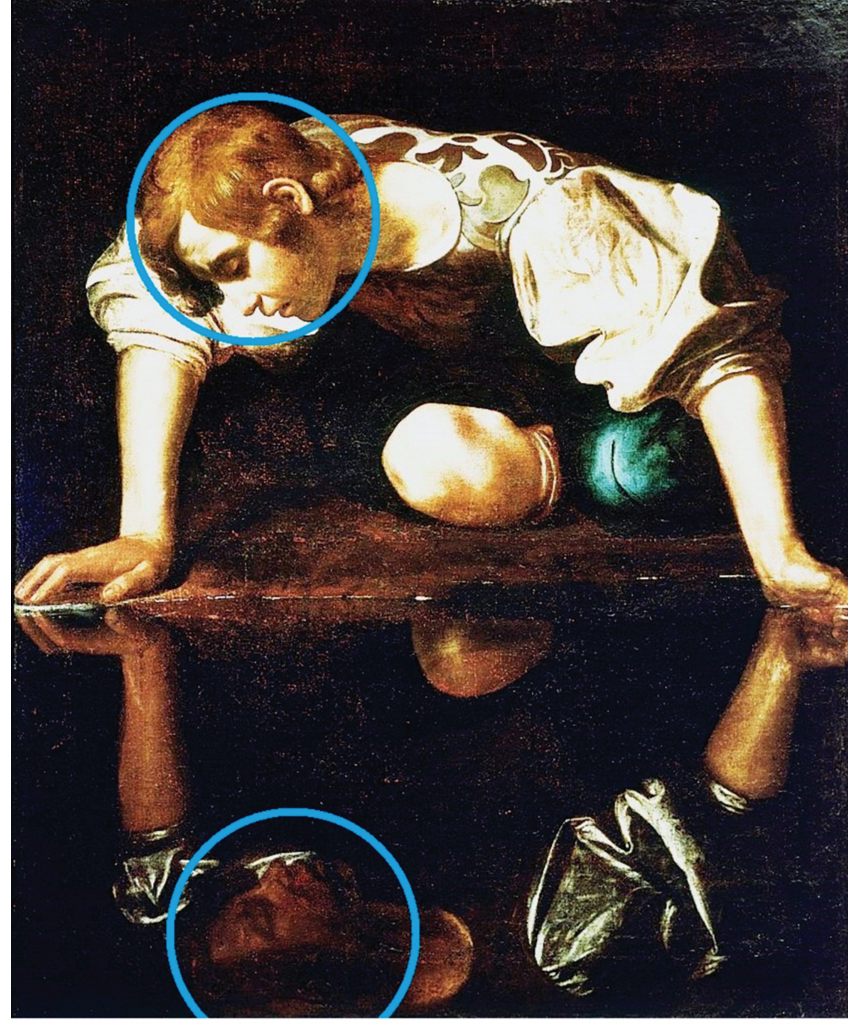

https://pt.wikipedia.org/wiki/Ficheiro:Narcissus-Caravaggio_(1594-96)_edited.jpg

Figura 1-A.4: O rosto da imagem de Narciso é menor do que o rosto de Narciso.

Narciso e da sua imagem são diferentes conforme as duas circunferências de mesmo raio, desenhadas sobre reprodução da obra de arte, ajudam a evidenciar na Figura 1-A.4.

Caravaggio então enxerga a imagem de Narciso um pouco menor do que vê Narciso. O que de fato interessa para a nossa visão são os tamanhos angulares dos objetos em relação aos nossos olhos e não as suas dimensões lineares absolutas. Objetos com tamanhos lineares iguais possuem tamanhos angulares em relação ao nosso olho diminuindo conforme estejam mais afastados. O tamanho angular de Narciso (alfa) é maior do que o tamanho angular da imagem de Narciso (beta) conforme a Figura 2-A.4

Medidas cuidadosas realizadas na Figuraura da Wikipedia que reproduz a obra de Caravaggio mostram que as dimensões da imagem de Narciso são um pouco menores do que as de Narciso. Portanto a pintura, além de ser uma belíssima obra de arte, é consistente com a Óptica Geométrica envolvida na visão.

Como não se dispunha de Narciso para lhe fazer uma foto, foi realizada a foto (Figura 3-A.4) do Pássaro Sedento na beira do espelho plano.

Assim sendo, se constata que a imagem registrada pela câmera fotográfica mostra que o Pássaro Sedento aparece maior do que a sua imagem virtual no espelho plano.

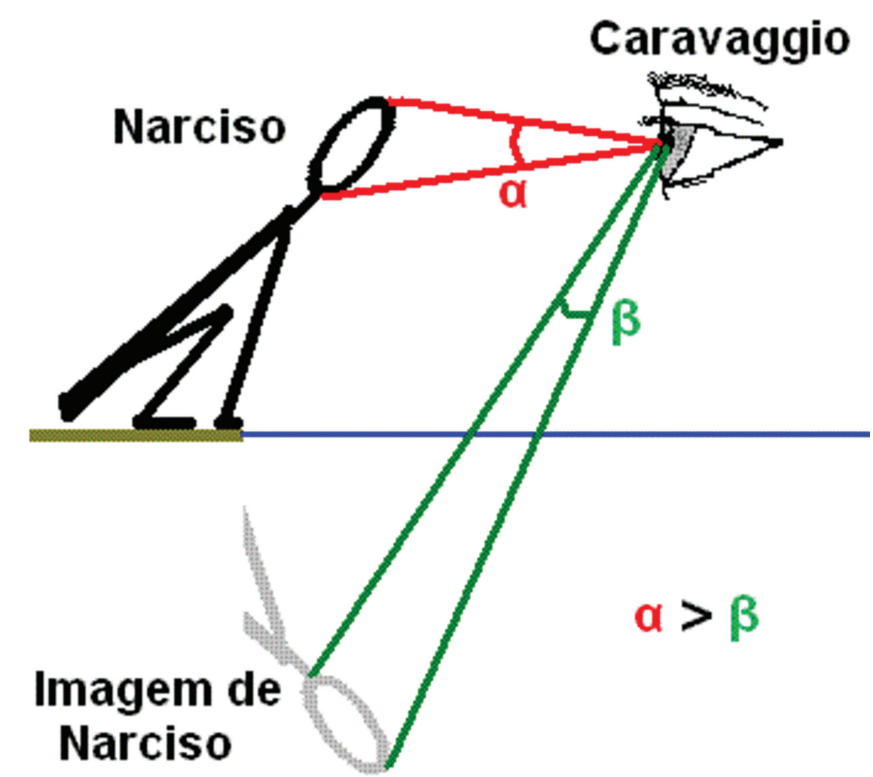

Figura 2-A.4: $O$ tamanho angular do rosto de Narciso em relação ao olho de Caravaggio é maior do que a imagem do rosto.

\section{A.5 - Cinemática: significado do tempo negativo https://urless.in/s4CzQ}

Por que não é comum nos problemas em física se ter como solução tempo com o valor negativo? Pois em uma análise o ponto zero poderia ser considerado o tempo de acionamento de um cronômetro e o instante negativo sendo os acontecimentos do fenômeno antes de acionar o cronômetro. Essa explicação seria correta?

\section{RESPOSTA:}

Sim, um tempo negativo significa um instante anterior a $t=0$ (caso orientemos o eixo dos $t>0$ para o futuro como é o usual). Se acionamos o cronômetro e arbitrariamente consideramos este momento como $t=$ 0 , então um $t<0$ indica um momento anterior ao acionamento.

Entretanto nem sempre um tempo negativo tem significado físico no modelo considerado, no equacionamento da situação cinemática de interesse. Um exemplo a seguir ajuda a esclarecer.

Imaginemos que o lançamento de uma bola seja realizado do topo de uma torre conforme esquematizado na Figura 1-A.5 Se modelarmos o movimento da bola como um movimento exclusivamente com a aceleração da gravidade e sendo $t=0$ o momento do lançamento, encontraremos uma equação do segundo grau em $t$ para a posição da bola no eixo vertical. Quando calcularmos o tempo para que a bola atinja o solo abaixo da torre, esta equação do segundo grau em t terá duas raízes, uma positiva e outra negativa. Neste caso a raiz negativa, que indica o momento em que a parábola descrita pela bola intercepta o nível do solo no passado, não tem significado neste modelo pois em $t<0$ a bola se encontrava na mão do lançador. 


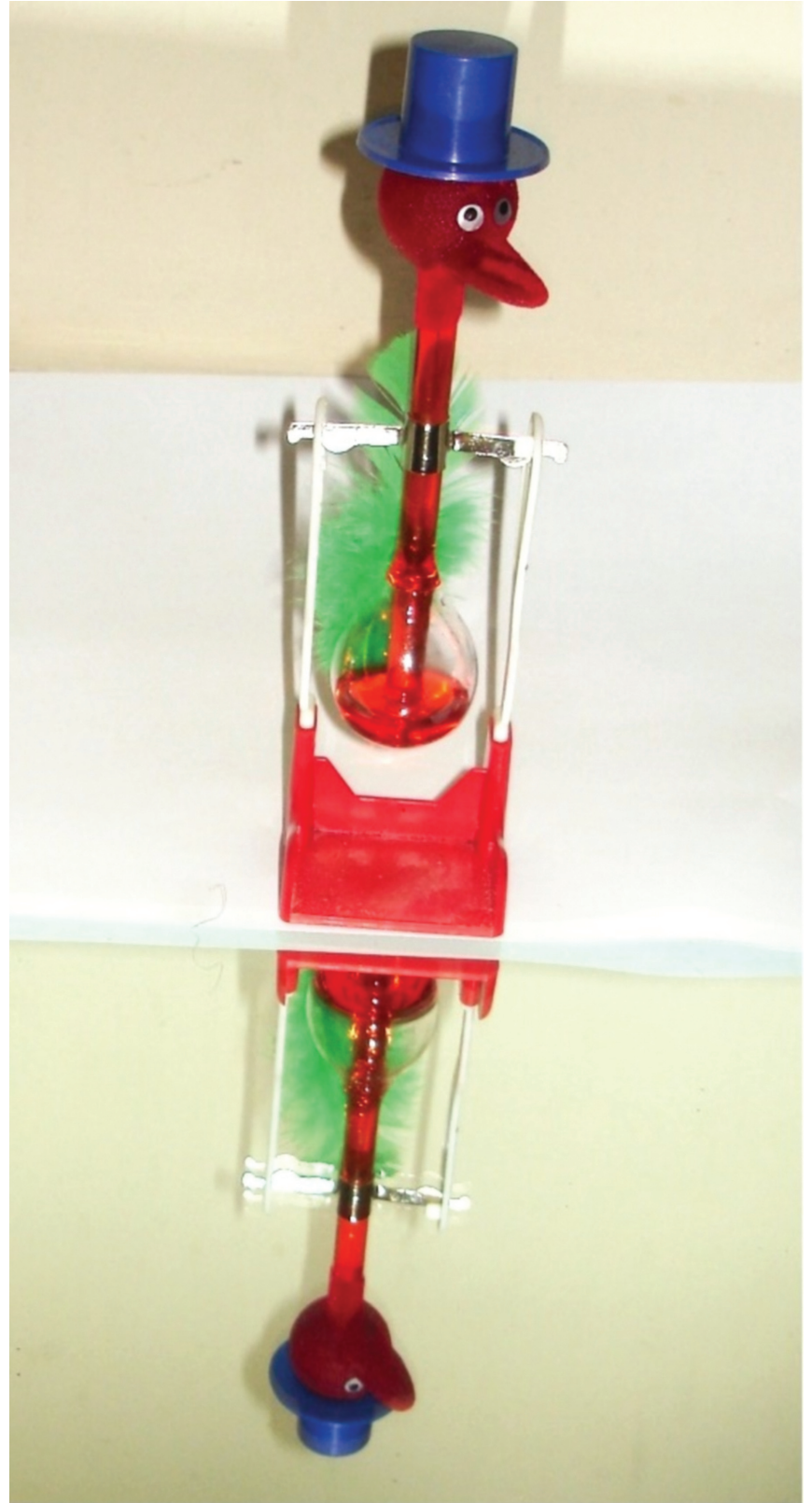

Figura 3-A.4: O Pássaro Sedento refletido no espelho plano.

Portanto nem todas as soluções de uma equação que satisfazem uma situação específica possuem significado no modelo de interesse. Tal se aplica inclusive quando todas as soluções para t são maiores do que zero. Encontradas as soluções, temos que analisar e decidir qual(is) o(s) resultado(s) para t que satisfazem todas as condições da nossa modelagem. E até pode acontecer que uma solução negativa em t seja a única adequada.

Comentário do perguntante: Excelente explicação. Realmente esclareceu a minha dúvida.

A.6 - Barco com ventilador solidário, desloca-se ou não? - https://urless.in/aVPkU

Professor, eu vi uma postagem do CREF mostrando que o barco a vela, com um ventilador

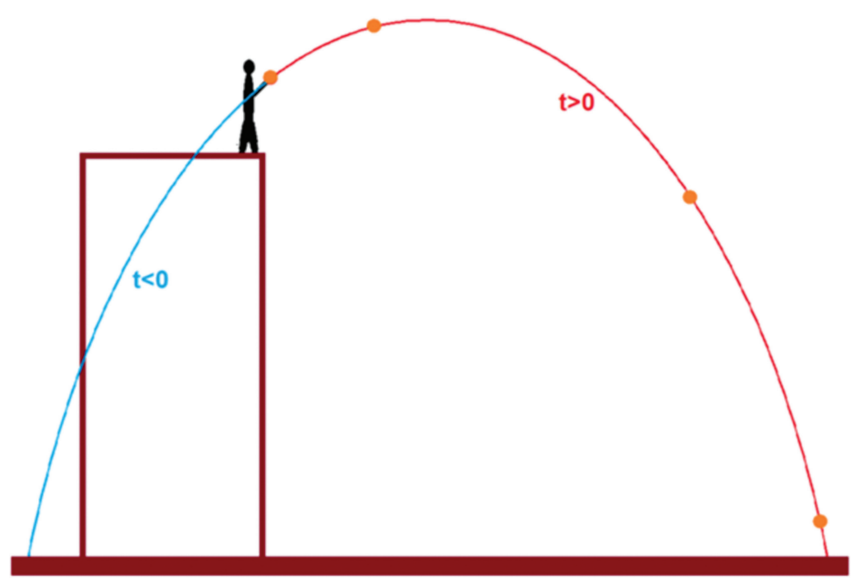

Figura 1-A.5: A parábola que descreve o movimento da bola lançada em $t=0$ do topo de uma torre intercepta o solo em dois locais e momentos distintos.

acoplado, se movimentaria. A postagem é Um barco a vela pode ser impelido pelo ar soprado sobre as velas por um ventilador instalado no próprio barco? (https://urless.in/kDBqe)

Isso contradiz o que me foi ensinado quanto ao corpo permanecer em repouso por ter as forças sendo aplicadas dele em nele mesmo, com aquele cansado exemplo de "você não consegue se puxar, pelos cabelos, para cima. Apenas o seu amigo consegue te puxar" ou "você, dentro da caixa, não consegue movimentar a caixa empurrando ela de dentro".

Por que, naquele caso, o carrinho se movimenta? Por que a força resultante não é nula? O ventilador não está solidário ao carrinho? E a vela sendo plana daria o mesmo resultado? Eu lembrei daqueles aerobarcos, e, se existem, é porque realmente funcionam. No caso deles o ventilador também está preso ao barco. Então por que o barco se movimenta sendo o ventilador parte do barco? Acho que a minha confusão está presa naquilo de não haver força resultante porque é o mesmo corpo. Mas como delimitar até onde seria o corpo? Está uma confusão. E, para efeito de vestibular, como as minhas questões que já fiz dessa situação que consideram a força resultante nula, o que eu deveria saber e decidir como escolha? Grata.

\section{RESPOSTA:}

O primeiro aspecto relevante é que o ventilador solidário ao barco age no ar que por sua vez age sobre a vela do barco. Então existe outro sistema envolvido além do barco com a vela e o ventilador solidário: o ar. Ou seja, o sistema barco com vela e ventilador solidário não é um sistema isolado e portanto, o somatório das forças sobre tal sistema pode não ser nulo.

Para que um corpo ou sistema esteja sob a ação de uma resultante de forças não nula tem que haver no mínimo um outro sistema, externo ao primeiro, lhe exercendo força. Neste caso existe no mínimo um 
agente externo ao sistema barco (ou carro) com vela e ventilador solidário e este agente é o ar.

$\mathrm{O}$ ar é impulsionado pelo ventilador mas quando se "choca com a vela" (o ar não precisa de fato se chocar com a vela mas apenas criar uma região de pressão mais alta nas proximidades da vela), dependendo da forma da vela e das condições do choque, pode produzir sobre a vela uma força com intensidade maior do que a força que o ventilador lhe aplicou. O limite superior para o impulso dado pelo ar à vela é duas vezes maior do que o impulso recebido do ventilador pelo ar conforme demonstramos em Um barco a vela pode ser propulsionado por um ventilador solidário ao barco que sopra em sua vela? (https://urless.in/uQJpu)

A imagem da Figura 1-A.6. retirada do vídeo que fizemos sobre este tema, indica esquematicamente a possibilidade de reversão do fluxo de ar pela vela, ocasionando um efeito importante de impulsionar o carro conforme visto no vídeo Barco a vela com ventilador (https://urless.in/uQJpu).

Para que o efeito ocorra de forma importante e perceptível (pois se ele for pequeno outras forças externas como as forças de atrito podem contrabalançá-lo) a vela deve ser capaz de reverter o fluxo de ar incidente sobre ela. Se a vela é plana, o efeito é nulo ou desprezível, isto é, o ar acaba por transferir à vela uma força de igual intensidade, mas sentido oposto à força de recuo do ventilador, resultando como caso particular que o barco permaneça em repouso. No vídeo Fan Cart with Sail (https://urless.in/U2tli) é demonstrado com uma vela plana que o carro pode ficar estacionado.

Infelizmente há questões de vestibular afirmando incondicionalmente a impossibilidade de um barco a vela ser impulsionado quando o ventilador, solidário ao barco, sopra sobre a vela. No nosso artigo anteriormente referido identificamos algumas questões equivocadas tratando do tema.

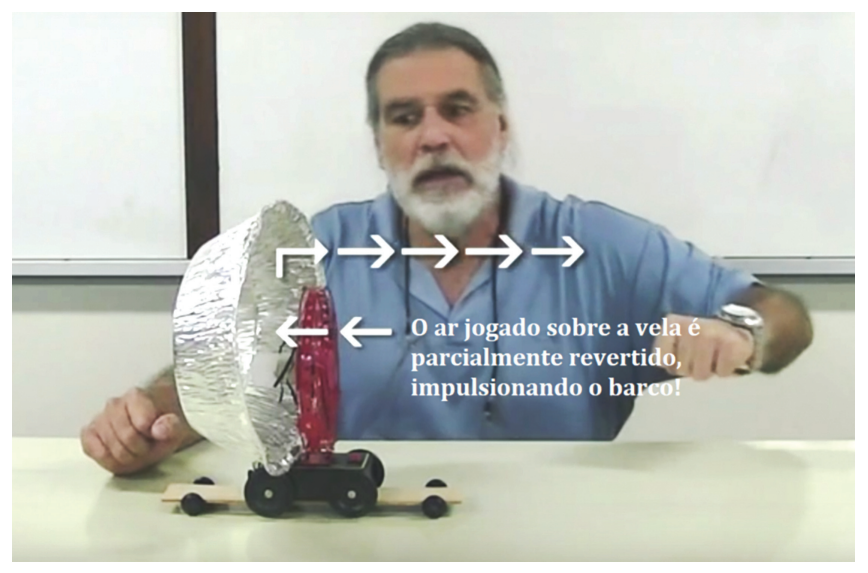

Figura 1-A.6: Ar jogado sobre a vela é parcialmente refletido.

\section{Referências}

[1] Este trabalho se constitui em uma atualização e ampliação do artigo de 2015 quando o Pergunte ao CREF completava cinco anos de existência, publicado em https://periodicos.ufsc.br/index.php/fisica/ article/view/2175-7941.2015v32n2p566/29955, acessado em 30 set. 2020 .

[2] Disponível em https://www.if.ufrgs.br/novocref/, acessado em 30 set. 2020.

[3] Disponível em https://br.answers.yahoo.com/, acessado em 30 set. 2020

[4] https://www.if.ufrgs.br/novocref/?page_id=215. acessado em 30 set. 2020.

[5] https://www.if.ufrgs.br/novocref/?page_id $=7505$ acessado em 30 set. 2020. 